\title{
Hormone Therapy Agent
}

National Cancer Institute

\section{Source}

National Cancer Institute. Hormone Therapy Agent. NCI Thesaurus. Code C147908.

Any agent that can alter hormone levels or modulate hormone effects. 